\title{
Medication burden of Saudi Arabian women receiving antiresorptive therapy
}

This article was published in the following Dove Press journal:

International Journal of Women's Health

27 August 2012

Number of times this article has been viewed

\author{
Mir Sadat-Ali ${ }^{1}$ \\ Bader Al-Shafie ${ }^{2}$ \\ Abdallah S Al-Omran' \\ Mohammed Q Azam' \\ 'Department of Orthopedic Surgery, \\ College of Medicine, University of \\ Dammam, Dammam, Saudi Arabia; \\ ${ }^{2}$ Department of Pharmacy, King Fahd \\ Hospital of the University, Al Khobar, \\ Saudi Arabia
}

Background and purpose: Osteoporosis is common in the Saudi Arabian population, and its successful treatment requires full compliance. Patients who require antiresorptive therapy, such as oral bisphosphonates, may suffer from other diseases requiring medications, which increases the medication burden and ends up in drug noncompliance on the part of patients, making them vulnerable to osteoporosis-related fractures. We decided to undertake this study to analyze the concomitant medications that osteoporotic patients are receiving at King Fahd Hospital of the University, Al Khobar.

Methods: Osteoporotic patients receiving antiresorptive therapy (ART) at King Fahd Hospital of the University, Al Khobar, were identified through the database of the QuadraMed Patient Care system and cross-checked with the radiology database of the dual-energy X-ray absorptiometry scan and pharmacy drug-dispensing system between January 2009 and December 2009. Concomitant medication is defined as the use of other drugs for $\geq 30$ days with oral bisphosphonates, calcium, and vitamin D. Medication burdens are defined as mild ( $\leq 1$ concomitant medication), moderate ( $\geq 2$ and $\leq 4$ medications), and severe ( $\geq 5$ medications). The demographic data, such as age, sex, and diagnosis, were collected from the medical records. The data were analyzed using the Statistical Package for the Social Sciences (SPSS).

Results: During the study period, 516 patients were diagnosed with osteoporosis, and 473 were on ART while the rest were using anabolic Teriperatide. Sixty-eight $(14.4 \%)$ of the patients, with an average age of $50.15 \pm 2.4$ years, were on one medication besides ART, vitamin D, and elemental calcium; $129(27.3 \%)$ of the patients, with an average age of $51.6 \pm 9.7$ years, were taking 3.32 medications, and 276 (58.3\%) of the patients, with a mean age of $62.1 \pm 10.7$ years, were on 8.02 concomitant medications. The most common concomitant medications in use were cardiac, endocrine, systemic nonsteroidal anti-inflammatory drugs, and analgesics, in that order. This study suggests that the majority of Saudi women who are osteoporotic and undergoing oral bisphosphonate therapy have a concomitant medication burden of $\geq 5$ other medications. For full compliance with the therapy, the patients' medication burden should be considered prior to selecting the treatment route.

Keywords: osteoporosis, concomitant medications, polypharmacy, compliance

\section{Introduction}

Osteoporosis is a progressive disease that weakens the bones and makes them highly susceptible to fracture. Drug therapy can slow or reverse the condition, but the duration of the therapy is long and has side effects. At present, bisphosphonates are the most commonly used drug. ${ }^{1-5}$ Adherence and compliance with osteoporosis medication has been poor, due to the dosing requirement and the adverse effects of the drugs. ${ }^{6}$ It was reported that $40 \%-45 \%$ of patients become noncompliant within the first six 
months of treatment with antiresorptives..$^{7-10}$ Noncompliance with osteoporotic medication appears to be universal, and recent data published in Saudi Arabia ${ }^{11}$ indicates that after 18 months of dispensing osteoporotic medications, not only was there no improvement in bone mineral density, but $10.4 \%$ of patients undergoing the therapy sustained fragility fractures within 16 months.

The strict, daily dosing instructions for oral bisphosphonates is believed to be the main reason for noncompliance, and this has led pharmaceutical companies to develop onceweekly and monthly dosages. ${ }^{12}$ Unfortunately, even after the introduction of weekly oral bisphosphonates, compliance has only increased marginally, to $65 \%,{ }^{13,14}$ which has caused physicians to seek out other possible causes of noncompliance. One such previously overlooked cause that was identified was that the medication burden (MB) in patients receiving bisphosphonate therapy made them noncompliant. ${ }^{15,16}$ Kaufman et al ${ }^{17}$ estimated that $12 \%$ of elderly US patients took $\geq 12$ medications, and $23 \%$ took at least five prescription medications, causing them either to have to change their regimens in order to accommodate oral bisphosphonates or to become noncompliant.

Although osteoporosis and postmenopausal osteoporosis in Saudi Arabian females and males is reported to be approximately $30 \%-35 \%$, the pattern of antiresorptive therapy and compliance is yet to be investigated. Moreover, the effect of $\mathrm{MB}$ on patients receiving therapy has not yet been studied in Saudi society. This study was undertaken in order to identify the number of concurrent medications that patients must take alongside oral bisphosphonates.

\section{Methods}

Osteoporotic patients receiving therapy at King Fahd Hospital of the University, Al Khobar, will be identified through the QuadMed Patient Care system's database and will be crosschecked with the Radiology database of the dual-energy X-ray absorptiometry scan and pharmacy drug-dispensing system between January 2009 and December 2009. Information about osteoporosis drug therapy (oral bisphosphonates, vitamin D, and calcium) and concomitant medications dispensed by the pharmacy were collected and entered into the database. Concomitant medication is defined as the use of other drugs for $\geq 30$ days with oral bisphosphonates, calcium, and vitamin $\mathrm{D}$. The MB is categorized into a mild burden ( $\leq 1$ concomitant medication), a moderate burden ( $\geq 2$ and $\leq 4$ medications), and a severe burden ( $\geq 5$ medications). The demographic data, such as age, sex, and diagnosis, were determined from the patients' medical records and were entered into the database. The data were analyzed using the Statistical Package for the Social Sciences (version 14.0; SPSS Inc, Chicago, IL).

\section{Results}

During the study period, 473 patients were on antiresorptive therapy (ART) and 43 patients were on injectable boneforming agents. The average age was $57.63 \pm 11$ years (range: 35-95 years) with a mean concomitant $\mathrm{MB}$ of 4.11. All patients were receiving monthly bisphosphonate with daily vitamin D and elemental calcium. Sixty-eight (14.4\%) of the patients, with an average age of $50.15 \pm 2.4$ years, were on one medication apart from the antiosteoporotic therapy. One hundred twenty-nine $(27.3 \%)$ of the patients, with an average age of $51.6 \pm 9.7$, years, were taking 3.32 medications (Figure 1). Figure 1 shows that the majority of the patients in this group were receiving between three and four concomitant medications. Two hundred seventy-six (58.3\%) of the patients, with a mean age of $62.1 \pm 10.7$ years, were on 8.03 concomitant medications (range: 5-29 medications) (Figure 2). In the group receiving $\geq 5$ medications, the majority of patients were taking between 5 and 15 concomitant medications. The most common concomitant medications in use were cardiac, endocrine, systemic anti-inflammatory drugs, and analgesics, in that order (Table 1).

\section{Discussion}

Osteoporosis is a major public health issue the world over, and it results in increased morbidity and mortality due to osteoporosis-related fractures. ${ }^{18,19}$ Effective treatment options for reducing fracture risk are available, provided that patients adhere to the osteoporotic therapy. High medication adherence has been found to reduce the risk of all clinical fractures by $20 \%-45 \%,{ }^{20,21}$ but nonadherence to

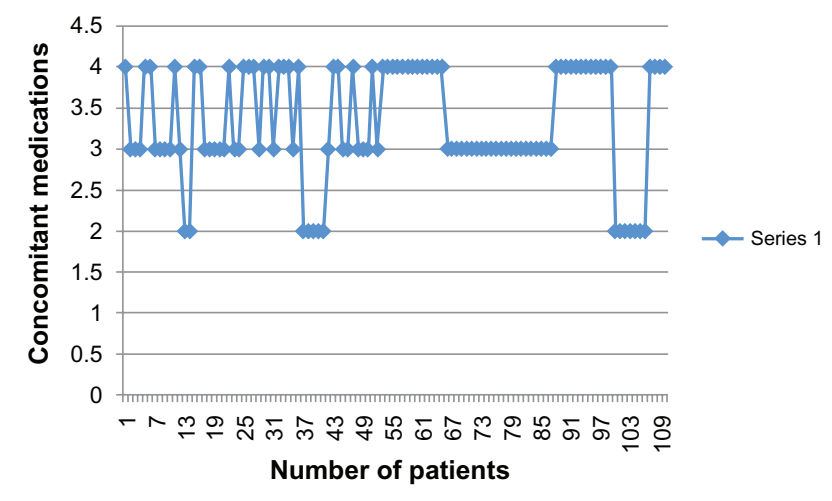

Figure I Concomitant medications and the number of patients in each group. 


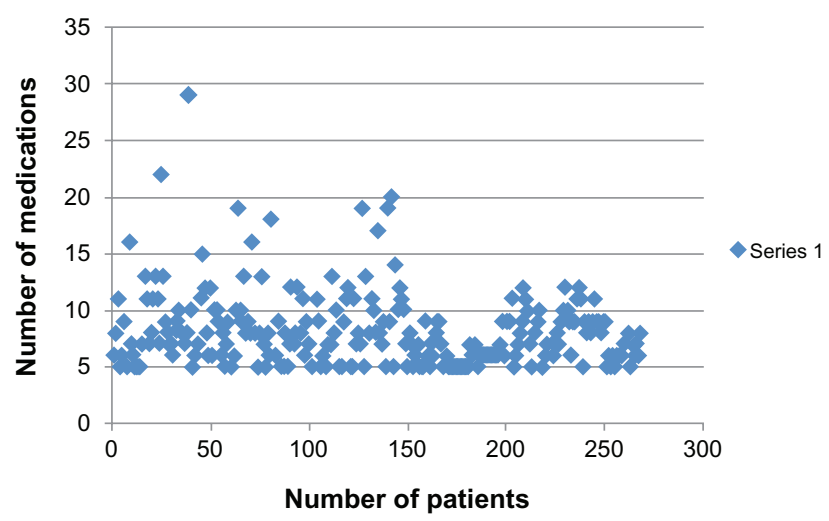

Figure 2 Number of medications versus number of patients.

the therapy has been a universal problem. Kothawala et $\mathrm{al}^{22}$ in a meta-analysis of 24 observational studies, found that overall adherence to osteoporosis therapies was $40 \%-60 \%$.

The causes of noncompliance with bisphosphonate therapy are multifactorial. The reasons strongly associated with noncompliance include the cost of drugs, the side effects of medication, the patients' perceptions of the effectiveness of therapy, ${ }^{23}$ the $\mathrm{MB}$ of patients taking osteoporotic medications, ${ }^{15,16}$ and the dosing regimens. In Saudi Arabia, the medications are distributed free of charge to all patients; hence, the cost of medications is not part of the equation, in terms of noncompliance. Therefore, there could be other causes of noncompliance, and our concern with $\mathrm{MB}$ as a cause of noncompliance with oral ART remains valid because it has not been studied enough among Saudi Arabian patients. We believe the issue of MB in Saudi patients appears to be an important one that needs to be addressed.

In adults in Great Britain, the $>75$-year age group takes a mean daily drug dosage of $2.5,{ }^{24}$ whereas Italians consume a mean dosage of 3.5 drugs daily ${ }^{25}$ and Danes a mean dosage of four drugs daily. ${ }^{26}$ In our study, Saudi $\geq 65$-year-old women with osteoporosis were taking additional daily

Table I The different types of concomitant medications

Cardiovascular drugs:

$60 \%$

(statins, diuretics, beta blockers calcium channel blockers,

antiarrhythmic drugs, plavix, aspirin)

Endocrine and antidiabetic

$45 \%$

(eltroxin, antidiabetes)

Osteodegenerative

(NSAIDs, aspirin)

Rheumatology

(MTX, vitamin D, calcium, steroids, NSAIDS)

Renal

(calcium, vitamin D, Imuran, cyclosporin, diuretics)

Abbreviations: NSAIDS, nonsteroidal anti-inflammatory drugs; MTX, methotrexate. medications at a mean of 7.78 , which in comparison to the reported literature, is high. Polypharmacy is defined as the use of five or more drugs, and the prevalence of polypharmacy in the United Kingdom was found to be $15 \%$ in patients over 75 years old, whereas in the Saudi population, it was $>50 \% .^{24}$

It takes two years or even more to assess objectively significant increases in bone density after instituting ART. Patients consuming five or more drugs are less likely to adhere to the drug regimen unless certain strategies are used. One such strategy is supervised injectable antiresorptive therapy, available in the form of subcutaneous injections every six months and annual intravenous injections. Both Denasumab and Zoledronic acid have proven potency with a wide safety profile, and are in clinical use worldwide. These drugs have been found to have the highest probabilities of being most efficacious in the prevention of nonvertebral and vertebral fractures. ${ }^{27}$ This will provide the clinician with a $100 \%$ guarantee of compliance and efficacy.

Limitations of the current study include the fact that the database was taken from the King Fahd Hospital of the University pharmacy to estimate the actual medications used by patients. It is assumed that the patients are taking the medications as prescribed to them and are following instructions. Furthermore, it is possible that patients are taking drugs from other institutions and retail pharmacies. Because King Fahd Hospital of the University is a tertiary care center, patients seen there will be similar to patients attending other centers. This study's strongest point is that it has raised the MB issue as it relates to the Saudi population; MB could be one of the most important factors in noncompliance with ART. We conclude that MB could be one of the most important factors of noncompliance, and should not be ignored. Physicians should be involved in tailoring osteoporotic therapy to ensure adherence to it. Considering the various findings of the present study, the authors believe that further prospective studies on the subject should be undertaken to assess MB among elderly populations and its impact on compliance.

Clearly, the issue of MB in patients taking oral ART is a valid one, and could be an important factor in noncompliance among Saudi Arabian patients. Physicians should play a major role in tailoring interventions for the individual patient, which should be aimed at promoting patient compliance. New treatment options, with semiannual and annual dosages, will change the future management of osteoporotic patients, provided these drugs remain safe, with fewer side effects in long-term use. 


\section{Disclosure}

The authors report no conflicts of interest in this work.

\section{References}

1. Rizzoli R. Long-term outcome of weekly bisphosphonates. Clin Orthop Relat Res. 2006;443:61-65.

2. Tosteson AN, Melton LJ III, Dawson-Hughes B, et al. Cost-effective osteoporosis treatment thresholds: the United States perspective [for the National Osteoporosis Foundation Guide Committee]. Osteoporosis Int. 2008;19:437-447.

3. Weiss TW, Henderson SC, McHorney CA, Cramer JA. Persistence across weekly and monthly bisphosphonates: analysis of US retail pharmacy prescription refills. Curr Med Res Opin. 2007;23(9): 2193-2203.

4. Van den Boogaard CH, Breekveldt-Postma NS, Borggreve SE, Goettsch WG, Herings RM. Persistent bisphosphonate use and the risk of osteoporotic fractures in clinical practice: a database analysis study. Curr Med Res Opin. 2006;22(9):1757-1764.

5. Borgstrom F, Carlsson A, Sintonen H, et al. The cost-effectiveness of risedronate in the treatment of osteoporosis: an international perspective. Osteoporos Int. 2006;17:996-1007.

6. Papaionnou A, Kennedy CC, Dolovich L, Lau E, Adachi JD. Patient adherence to osteoporosis medications: problems, consequences and management strategies. Drugs Aging. 2007;24(1):37-55.

7. Solomon DH, Avorn J, Katz JN, et al. Compliance with osteoporosis medications. Arch Intern Med. 2005;165:2414-2419.

8. Hamilton B, McCoy K, Taggart H. Tolerability and compliance with residronate in clinical practice. Osteoporos Int. 2003;14:259-1262.

9. Tosteson AN, Grove MR, Hammond CS, et al. Early discontinuation of treatment for osteoporosis. Am J Med. 2003;115:209-216.

10. Cramer JA, Silverman S. Persistence with bisphosphonate treatment for osteoporosis. Am J Med. 2006;119(4 Suppl 1):S12-S17.

11. Sadat-Ali M, Al-Dakheel D, Al-Turki HA, Al-Elq A. Can drug therapy alone increase bone mineral density and reduce the incidence of osteoporosis-related fractures? Ind Pract. 2009;62(8):507-510.

12. Miller PD. Optimizing the management of postmenopausal osteoporosis with bisphosphonates: the emerging role of intermittent therapy. Clin Ther. 2005;27:361-376.

13. Recker RR, Gallagher R, MacCosbe PE. Effect of dosing frequency on bisphosphonate medication adherence in a large longitudinal cohort of women. Mayo Clin Proc. 2005;80:856-861.
14. Cramer JA, Amonkar MM, Hebborn A, Altman R. Compliance and persistence with bisphosphonate dosing regimens among women with postmenopausal osteoporosis. Curr Med Res Opin. 2006;21:1453-1460.

15. Gurwitz JH. Polypharmacy: a new paradigm for quality drug therapy in the elderly. Arch Intern Med. 2004;164:1957-1959.

16. Rollason V, Vogt N. Reduction of the polypharmcy in the elderly: a systematic review of the role of the pharmacist. Drugs Aging. 2003;20: 817-832.

17. Kaufman DW, Kelly JP, Rosenberg L, et al. Recent pattern of medication use in the ambulatory adult population of the United States: the Slone survey. JAMA. 2002;287:337-344.

18. US Department of Health and Human Services. Bone Health and Osteoporosis: A Report of the Surgeon General. Rockville, MD: US Department of Health and Human Services, Office of the Surgeon General; 2004.

19. Burge R, Dawson-Hughes B, Solomon DH, et al. Incidence and economic burden of osteoporosis-related fractures in the United States, 2005-2025. J Bone Miner Res. 2007;22:465-475.

20. Siris ES, Harris ST, Rosen CJ, et al. Adherence to bisphosphonate therapy and fracture rates in osteoporotic women: relationship to vertebral and nonvertebral fractures from 2 US claims databases. Mayo Clin Proc. 2006;81(8):1013-1022.

21. Penning-van Beest FJ, Erkens JA, Olson M, Herings RM. Loss of treatment benefit due to low compliance with bisphosphonate therapy. Osteoporos Int. 2008;19(4):511-517.

22. Kothawala P, Badamgarav E, Ryu S, Miller RM, Halbert RJ. Systematic review and meta-analysis of real-world adherence to drug therapy for osteoporosis. Mayo Clin Proc. 2007;82(12):1493-1501.

23. McHorney CA, Schousboe JT, Cline RR, Weiss TW. The impact of osteoporosis medication beliefs and side-effect experiences on nonadherence to oral bisphosphonates. Curr Med Res Opin. 2007;23(12): 3137-3152.

24. Chen YF, Dewey ME, Avery AJ. Self-reported medication use for older people in England and Wales. J Clin Pharm Ther. 2001;26:129-1240.

25. Nobili A, Tettamanti M, Frattura L, et al. Drug use by the elderly in Italy. Ann Pharmacother. 1997;31:416-422.

26. Barat I, Andreasen F, Damsgaard EM. The consumption of drugs by 75 -year-old individuals living in their own homes. Eur J Clin Pharmacol. 2000;56:501-509.

27. Hopkins RB, Goeree R, Pullenayegum E, et al. The relative efficacy of nine osteoporosis medications for reducing the rate of fractures in post-menopausal women. BMC Musculoskelet Disord. 2011; 12:209.
International Journal of Women's Health

\section{Publish your work in this journal}

The International Journal of Women's Health is an international, peerreviewed open-access journal publishing original research, reports, reviews and commentaries on all aspects of women's healthcare including gynecology, obstetrics, and breast cancer. Subject areas include: Chronic conditions (migraine headaches, arthritis, osteoporosis);

\section{Dovepress}

Endocrine and autoimmune syndromes; Sexual and reproductive health; Psychological and psychosocial conditions. The manuscript management system is completely online and includes a very quick and fair peer-review system. Visit http://www.dovepress.com/ testimonials.php to read real quotes from published authors. 